\title{
ScIDice
}

\author{
International Journal of Dentistry and Oral Science (IJDOS) \\ ISSN: 2377-8075
}

\section{Effect Of Indian Spices On Colour Stability Of Two Commercially Available Glass Ionomer Cements - An In Vitro Study}

Research Article

R Shruthi Devi ${ }^{1}$, Jayalakshmi ${ }^{2 *}$, Balaji Ganesh $S^{3}$, Sasidharan $S^{4}$

${ }^{1}$ Saveetha Dental College and Hospitals, Saveetha Institute of Medical and Technical Sciences (SIMATS), Saveetha University, Chennai- 77, India.

${ }^{2}$ Reader, White lab - Material Research Centre, Saveetha Dental College and Hospitals, Saveetha Institute of Medical and Technical Sciences [SIMATS], Saveetha University, Chennai- 77, India.

${ }^{3}$ Senior Lecturer, White lab - Material Research Centre, Saveetha Dental College and Hospitals, Saveetha Institute of Medical and Technical Sciences [SIMATS], Saveetha University, Chennai- 77, India.

${ }^{4}$ Tutor, White lab - Material Research Centre, Saveetha Dental College and Hospitals, Saveetha Institute of Medical and Technical Sciences [SIMATS], Saveetha University, Chennai- 77, India.

\section{Abstract}

Introduction: Recent advancements have been made in the field of dental aesthetics for repairing damaged teeth producing a flawless appearance. Colour stability is an important property that assess success or failure of treatment. GIC is a restorative material that has physico-chemical bonding to both enamel and dentin and is similar to colour of natural teeth. Our study aims to find out the colour stability by comparing two different brands of GIC in turmeric and chilli powder and analysing their results.

Materials and Methods: Two commercially available GIC Pyrax and DTech were taken for the study. A total of 12 disc shaped samples, 6 from each with dimensions $10 \mathrm{~mm}$ and $2 \mathrm{~mm}$ in thickness were made. Required quantities of turmeric, chilli powder were immersed in glass beakers containing turmeric solution, chilli solution and distilled water separately, 4 samples in each for $24 \mathrm{hrs}$ then checked for colour stability values using spectrophotometer and analysed statistically by unpaired test using SPSS software version 23.0.

Results: In chilli solution, $\Delta \mathrm{E}$ value of $\mathrm{D}$ tech - 8.92 which was lesser than pyrax - 14.97. On the other hand, in turmeric solution, $\Delta \mathrm{E}$ value of Dtech was 18.90 which was significantly higher than pyrax which was 17.86 . In Control Dtech and pyrax was found to be 7.51 and 14.51 respectively. P Value $=0.00<0.05$ (statistically significant).

Conclusion: On comparing the three groups, GIC samples stained with turmeric were least colour stable.

Keywords: Colour Stability; Chilli; Dtech; Eco Friendly Gic; Innovative Technology; Indian Spices; Pyrax; Turmeric.

\section{Introduction}

In today's world, well contoured, aligned, white teeth are considered to give beauty and many dentists have turned their attention towards it in order to achieve it. Anomalies in size, shape, colour and structure of dentition have led to various problems like decreased masticatory efficiency, speech disturbances and psychological problems. Thus restoring a damaged or decayed tooth is important [1]. Recent technological advancements have been made in the field of dental aesthetics for augmenting and repairing damaged teeth thereby producing a flawless appearance. Among the various restorative materials used, composite, glass ionomers are the most commonly used as these materials are closely related to the natural teeth in terms of colour and hence has a wide acceptance among the young people with high incidence of caries $[2,3]$. It also stimulates the natural teeth and restores cavitated lesions in both primary and permanent dentition [4]. But the main challenge in clinical practice is to maintain longevity and appearance [5]. Colour stability is an important property that assess success or failure of treatment and mostly attributed mainly to the anterior dental restorations and water sorption and the alteration of colour is mostly attributed to the oral hygiene, dietary habits of an individual. The discoloration is mainly caused due to stain accumulation and surface roughness which are considered as ex-

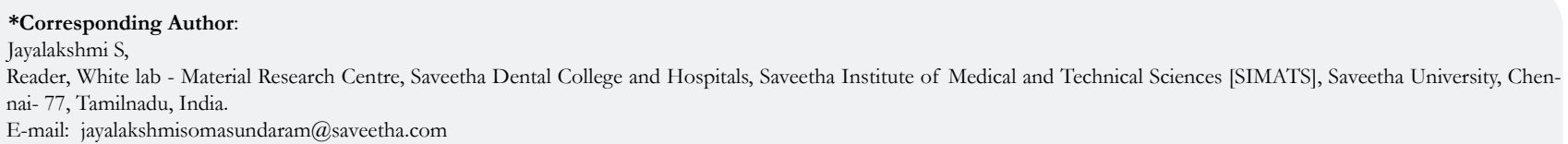

Copyright: Jayalakshmi $\mathbf{S}^{\odot}$ 2021. This is an open-access article distributed under the terms of the Creative Commons Attribution License, which permits unrestricted use, distribution and reproduction in any medium, provided the original author and source are credited. 
trinsic factors and water sorption, degradation and dissolution of ingredients as the intrinsic factors. It is also based on the type of resin used, size of fillers and also the food consumed $[6,7]$.

Processed food and beverages affect colour stability apart from causing diabetes, obesity and cardiovascular (CVS) diseases due to the presence of a wide range of colouring agents [8]. Though fluoride releasing aesthetic restorative materials have been used extensively, colour stability still poses a great challenge to the dentists due to the dynamic environment of the oral cavity. For suitable performance, longevity and clinical success, the choice of material to be chosen must possess inherent characteristics [9]. The use of bleaching agents like hydrogen peroxide, carbamide peroxide are used to restore the discoloration [10]. Hence an ideal esthetic restorative material should mimic the natural tooth in all terms like colour, translucency, surface texture and colour stability for a long period of time [11].

Indian culture is considered to be one of the areas of abundant flavours and colours where Indian spice is present one among them. The most abundant micronutrients commonly called polyphenols present in spices leads to the staining of teeth. It is a large class of chemical compounds in plants that is made of one or more polyphenol units. Turmeric is considered the ancient golden spice of India and commonly called the kitchen queen. Curcumin compound present in turmeric gives yellow colour. Other than this, turmeric contains polyphenols, terpenes flavonoids etc. Chilli powder is used as a flavouring agent and the important characteristic present is the colour and pungency. The carotenoid pigments present in chilli give its red colour. Drying of chilli leads to loss of colour and texture of the final product formed as surface colour is important while purchasing the powder. GIC is a type of restorative material that has low coefficient of thermal expansion, physico chemical bonding to both enamel and dentin. Since there are less studies based on immersing GIC in spice. Our study aims to find out the colour stability by comparing two different brands of GIC in turmeric and chilli powder and analysing their results.

\section{Materials and Methods}

\section{Preparation of specimens:}

Two types of GIC were taken for this study. One was D-tech and the other one was Pyrax.A total of 12 disc shaped samples, 6 from each type.(Fig. 1) These GIC specimens were prepared by dispensing the powder and the liquid in proper proportion according to the manufacturer's instructions and then were loaded into PTFE(Polytetrafluorethylene (teflon)) moulds and allowed to set. They were retrieved from the molds after hardening and the excess flash if present were trimmed and smoothened with the help of polishing bur and micromotor. Only the specimens which were found to have smooth surface finish were taken further for performing the experiment.

\section{Preparation of Staining or immersing solutions:}

Required quantities of turmeric, chilli powder were weighed and taken in a beaker and made to dissolve in $100 \mathrm{ml}$ of distilled water. (Fig. 2).

\section{Immersing method:}

The hydrated specimens were immersed in glass beakers containing the turmeric solution, chilli solution and distilled water separately, 4 samples in each solution. The specimen immersed in distilled water was taken as the control for $24 \mathrm{hrs}$. Then they were rinsed with distilled water and were checked for colour stability using a Vita easy shade advance spectrophotometer.(Fig. 3).

\section{Calculation of colour stability:}

For determination of colour stability, a spectrophotometer of reflection time was used for measuring the colour changes $(\Delta \mathrm{E})$ based on the Commission Internationale de l' Eclairage lab(CIELAB) system in 1976. The CIELAB colour space also referred to as $\mathrm{L}^{*} \mathrm{a}^{*} \mathrm{~b}$. $\mathrm{L}^{*}$ for perceptual lightness, represents the lightness to darkness values that range from 0 to 100 . $\mathrm{a}^{*}$ and $\mathrm{b}^{*}$ for the four unique colours that can be seen by the human vision, where, $a^{*}$ represents the greenness to redness with values of -127 to +128 and $b^{*}$ represents the blueness to yellowness with values of -127 to +128 . The colour values of specimens before immersing were considered as baseline. The $\mathrm{L}, \mathrm{a}, \mathrm{b}$ values were obtained from the Vita EasyShade Spectrophotometer (fig 1) for the colour stability. The $\Delta \mathrm{E}$ values were calculated in order to determine the degree of alteration in colour at different stages. Then pre and post immersion values were compared and analysed using SPSS software version 23.0 The formula used is

$$
\Delta \mathrm{E}\left(\mathrm{L}^{*} \mathrm{a}^{*} \mathrm{~b}^{*}\right)=\left[\left(\Delta \mathrm{L}^{*}\right)^{2}+(\Delta \mathrm{a})^{2}+(\Delta \mathrm{b})^{2}\right]
$$

\section{Results}

Table 1 showed the significant testing on colour stability on Dtech and Pyrax by turmeric. Unpaired T test was used.It was found that the mean value of Dtech and Pyrax was 18.9 and 17.86 with a standard deviation of 2.65 and 0.26 respectively with a $p$ value of 0.00 hence considered statistically significant. Table 2 showed the significant testing on colour stability on Dtech and Pyrax by

Figure 1, 2. Different brands of GIC Dtech and pyrax before immersion in the spices solution.

A) Dtech

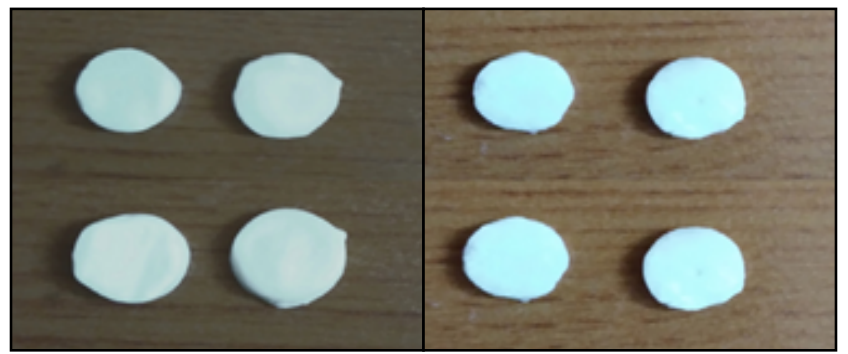


Figure 2. Samples immersed in chilli and turmeric solutions respectively.

A) Chilli

B) Turmeric

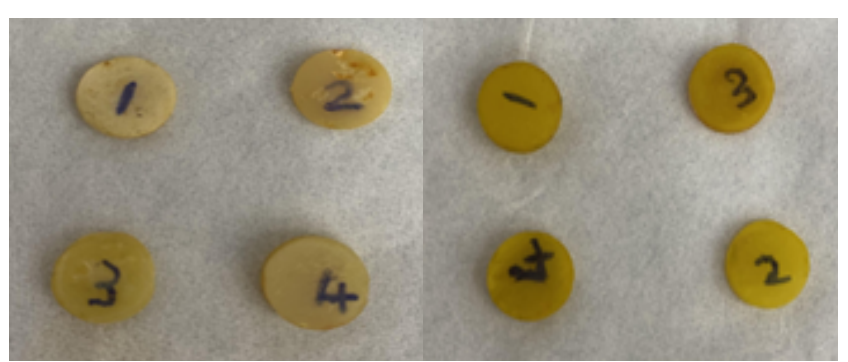

Figure 3. Vita EasyShade Spectrophotometer used for assessing the colour stability.

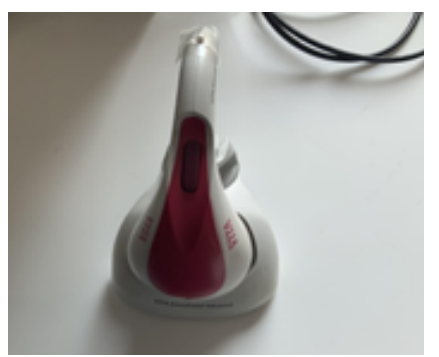

Graph 1. The graph shows the association between the mean value of colour stability of Dtech and pyrax when immersed in turmeric solution. The $\mathrm{X}$ axis depicts GIC brand and the $\mathrm{y}$ axis depicts mean values. The blue colour represents Pyrax and yellow represents Dtech. It is seen that the mean value of colour stability of DTech and Pyrax when immersed in turmeric was 18.90 and 17.86 respectively. Hence, turmeric produced greater colour stability in pyrax when compared to Dtech.

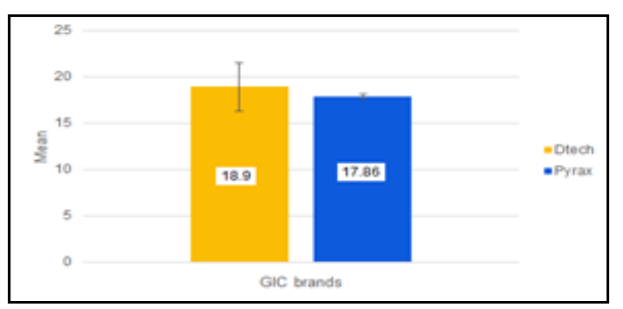

Graph 2. The graph shows the association between the mean value of colour stability of Dtech and pyrax when immersed in turmeric solution. The $\mathrm{X}$ axis depicts GIC brand and the $\mathrm{y}$ axis depicts mean values. The blue colour represents Pyrax and yellow represents Dtech. It is seen that the mean value of colour stability of DTech and Pyrax when immersed in Chilli was found to be 8.92 and 14.97 respectively. Hence, Chilli produced greater colour stability in Dtech than in Pyrax.

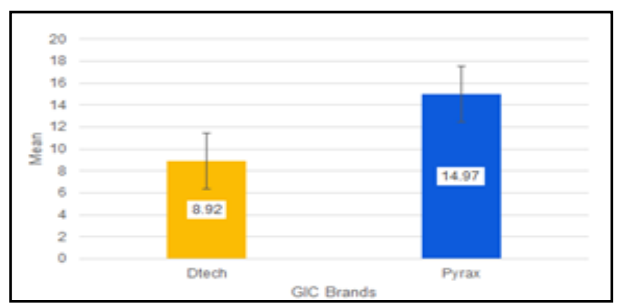

Table 1. It shows significant testing on colour stability on Dtech and Pyrax by turmeric. Unpaired $T$ test was used and $p$ value of 0.05 or less than that is considered statistically significant.

\begin{tabular}{|c|c|c|c|c|c|}
\hline \multicolumn{2}{|c|}{ Groups } & N & Mean & Std. Deviation & Significance \\
\hline \multirow{2}{*}{ Turmeric Delta E } & D-tech & 2 & 18.9 & 2.659 & 0 \\
\cline { 2 - 5 } & Pyrax & 2 & 17.86 & 0.269 & \\
\hline
\end{tabular}

Table 2. It shows significant testing on colour stability on Dtech and Pyrax by chilli. Unpaired T test was used and $\mathrm{p}$ value of 0.05 or less than that is considered statistically significant.

\begin{tabular}{|c|c|c|c|c|c|}
\hline \multicolumn{2}{|c|}{ Groups } & $\mathrm{N}$ & Mean & Std. Deviation & Significance \\
\hline \multirow{2}{*}{$\begin{array}{c}\text { Chilli delta } \\
\text { E }\end{array}$} & D-tech & 2 & 8.92 & 0.905 & 0 \\
\cline { 2 - 5 } & Pyrax & 2 & 14.975 & 2.553 & \\
\hline
\end{tabular}


chilli. Unpaired T test was used and p value of 0.05 or less than that is considered statistically significant. It was found that the mean value of Dtech and Pyrax was 8.92 and 14.97 with a standard deviation of 0.905 and 0.255 respectively with a $p$ value of 0.00 ,hence considered statistically significant.

From the two graphs above, it can be seen that both $\mathrm{D}$ tech and pyrax were more stained in turmeric. The descending order in which Dtech was stained in immersing solutions are as follows Turmeric $>$ chilli. A similar trend was found with pyrax also in the following order Turmeric $>$ chilli. But on comparing their colour stability it was found that Dtech showed more colour stability in chilli solution and pyrax in turmeric because in chilli solution the $\Delta \mathrm{E}$ value of $\mathrm{D}$ tech was 8.92 which was lesser than pyrax which was 14.97. On the other hand, in turmeric solution, the $\Delta \mathrm{E}$ value of Dtech was found to be 18.90 which was significantly higher than pyrax which was 17.86 . So it can be said that turmeric stains both Dtech and pyrax intensely when compared to other spice as the $\mathrm{p}$ value was $>0.05$.

\section{Discussion}

Our team has extensive knowledge and research experience that has translated into high quality publications [12-31]. Turmeric is a widely used spice in India due to its various therapeutic properties. The major constituent curcumin present gives it the required yellow colour. In the current study, it was shown that turmeric showed overall higher staining when compared to chilli thereby producing least colour stability. The results also indicated that the colour change values were statistically different between Dtech and pyrax when stained with both turmeric and chilli. A similar study was found were NC (New compomer) and RMGIC (Resin modified glass ionomer cement) produced statistically different values when immersed in turmeric and that the maximum staining was produced by NC than GIC when immersed in turmeric which contradicted our study. The degree of colour change can differ between products and categories of the materials used [32]. Other studies based on colour stability with indigenous spices $[33,34]$ showed that turmeric stained the resin based composites more than the other spices like chilli powder, tamarind, tobacco etc. which was similar to our study as in our study turmeric was found to stain GIC more than other spices but on comparing the color stability, chilli produced good results as overall delta $\mathrm{E}$ value was lower than in turmeric solution.

GIC contains a certain amount of water within their structure loosely bound that gets easily removed by dehydration while those that are tightly bound are not affected by dehydration and stays even after the reaction gets completed thereby producing higher staining resistance [35]. It can replace RMGIC for luting crowns, bridges and other small restorations. An ideal restorative material must exhibit adequate esthetics as a colour stability function in addition to other properties like strength and biocompatibility and at the same time it aids in the preventing the secondary caries formation [36] are used to quantify the tooth colour as it might potentially eliminate all the subjective aspects of colour assessment. The American Dental association suggests using CIELAB colour coding system for assessing chromatic differences [37]. In the present study, colour evaluations was made by using the Vita shade spectrophotometer (fig 1) using this CIELAB coding system as it was found useful in providing information about the location of a object colour in $3 \mathrm{D}$ space in terms of 3 coordinate values $L^{*}, a^{*}$ and $b^{*}$ where $L^{*}$ represents the value of brightness and $a^{*}$ and $b^{*}$ represents the numeric correlates. The magnitude of colour difference $\Delta \mathrm{E}$ obtained from these values. It was found that higher the $\Delta \mathrm{E}$ value, greater is the difference between the 2 samples that are being compared [38].

Though colour stability of GIC in various immersing solutions have gained interest among the researchers, the staining influence using turmeric and chilli has not been reported much. Hence, the present study was carried out to evaluate the effect of colour stability of Dtech and pyrax when immersed in turmeric and chilli solutions. The limitation of the study was small sample size and the immersing solutions used to compare were also less. So further studies based on large sample size to be done for the effectiveness of turmeric of the study as Glass ionomer cement (luting cement)are found to replace resin modified GIC for luting crowns, bridges and tooth coloured restorative materials.

\section{Conclusion}

The present study evaluated the influence of turmeric and chilli on the colour stability of Dtech and Pyrax glass ionomer cement and compared their effects when immersed and hence, on comparing the three groups, GIC samples stained with turmeric were least colour stable.

\section{Acknowledgement}

The first author is grateful to white lab for helping in complete the work

\section{Funding}

- Saveetha Dental College and Hospitals, Saveetha Institute of Medical and Technical Sciences, Saveetha University, Chennai

- Harshini Hospital, Madurai

\section{References}

[1]. Sahana S, Vasa AA, Sekhar R, Prasad K. Esthetic crowns for primary teeth: A review. Ann Essences Dent. 2010 Apr 13;2(2):87-93.

[2]. Villalta P, Lu H, Okte Z, Garcia-Godoy F, Powers JM. Effects of staining and bleaching on color change of dental composite resins. J Prosthet Dent. 2006 Feb 1;95(2):137-42.

[3]. Papagiannoulis L, Kakaboura A, Eliades G. In vivo vs in vitro anticariogenic behavior of glass-ionomer and resin composite restorative materials. Dent Mater. 2002 Dec;18(8):561-9.Pubmed PMID: 12385896.

[4]. Yoonis E, Kukletová M. Tooth-colored dental restorative materials in primary dentition. Scripta Medica. 2009;82(2):108-4.

[5]. Pjetursson BE, Sailer I, Zwahlen M, Hämmerle CH. A systematic review of the survival and complication rates of all-ceramic and metal-ceramic reconstructions after an observation period of at least 3 years. Part I: single crowns. Clin Oral Implants Res. 2007 Jun;18:73-85.

[6]. Abu-Bakr N, Han L, Okamoto A, Iwaku M. Color stability of compomer after immersion in various media. J Esthet Dent. 2000;12(5):258-63.Pubmed PMID: 11338492.

[7]. Barutcigil Ç, Yıldız M. Intrinsic and extrinsic discoloration of dimethacrylate and silorane based composites. J Dent. 2012 Jul;40 Suppl 1:e57-63. Pubmed PMID: 22239912.

[8]. Koleoso ON, Ehigie BO, Akhigbe KO. Colour preference among children in a Nigerian Montessori School. Mediterr J Soc Sci . 2014 Jan 5;5(1):325.

[9]. Hotwani K, Thosar N, Baliga S. Comparative in vitro assessment of color stability of hybrid esthetic restorative materials against various children's bev- 
erages. J Conserv Dent. 2014 Jan;17(1):70-4.Pubmed PMID: 24554866.

[10]. Hatanaka GR, Abi-Rached Fde O, Almeida-Júnior AA, Cruz CA. Effect of carbamide peroxide bleaching gel on composite resin flexural strength and microhardness. Braz Dent J. 2013;24(3):263-6.Pubmed PMID: 23969917.

[11]. Padiyar N. Colour stability: An important physical property of esthetic restorative materials. Int. j. clin. dent. sci. 2010;1(1).

[12]. Muthukrishnan L. Imminent antimicrobial bioink deploying cellulose, alginate, EPS and synthetic polymers for 3D bioprinting of tissue constructs. Carbohydr Polym. 2021 May 15;260:117774.Pubmed PMID: 33712131.

[13]. PradeepKumar AR, Shemesh H, Nivedhitha MS, Hashir MMJ, Arockiam $S$, Uma Maheswari TN, et al. Diagnosis of Vertical Root Fractures by Conebeam Computed Tomography in Root-filled Teeth with Confirmation by Direct Visualization: A Systematic Review and Meta-Analysis. J Endod. 2021 Aug;47(8):1198-1214.Pubmed PMID: 33984375.

[14]. Chakraborty T, Jamal RF, Battineni G, Teja KV, Marto CM, Spagnuolo G. A Review of Prolonged Post-COVID-19 Symptoms and Their Implications on Dental Management. Int J Environ Res Public Health. 2021 May 12;18(10):5131.Pubmed PMID: 34066174.

[15]. Muthukrishnan L. Nanotechnology for cleaner leather production: a review. Environmental Chemistry Letters. 2021 Jan 13;19(3): 2527-49.

[16]. Teja KV, Ramesh S. Is a filled lateral canal - A sign of superiority? J Dent Sci. 2020 Dec;15(4):562-563.Pubmed PMID: 33505634.

[17]. Narendran K, MS N, SARVANAN A, SUKUMAR E. Synthesis, Characterization, Free Radical Scavenging and Cytotoxic Activities of Phenylvilangin, a Substituted Dimer of Embelin. Indian J. Pharm. Sci. 2020 Sep 1;82(5).

[18]. Reddy P, Krithikadatta J, Srinivasan V, Raghu S, Velumurugan N. Dental Caries Profile and Associated Risk Factors Among Adolescent School Children in an Urban South-Indian City. Oral Health Prev Dent. 2020 Apr 1;18(1):379-386.Pubmed PMID: 32618460.

[19]. Sawant K, Pawar AM, Banga KS, Machado R, Karobari MI, Marya A, et al. Dentinal Microcracks after Root Canal Instrumentation Using Instruments Manufactured with Different NiTi Alloys and the SAF System: A Systematic Review. Appl. Sci. 2021 Jan;11(11):4984.

[20]. Bhavikatti SK, Karobari MI, Zainuddin SLA, Marya A, Nadaf SJ, Sawant VJ, et al. Investigating the Antioxidant and Cytocompatibility of Mimusops elengi Linn Extract over Human Gingival Fibroblast Cells. Int J Environ Res Public Health. 2021 Jul 4;18(13):7162.Pubmed PMID: 34281099.

[21]. Karobari MI, Basheer SN, Sayed FR, Shaikh S, Agwan MAS, Marya A, et al. An In Vitro Stereomicroscopic Evaluation of Bioactivity between Neo MTA Plus, Pro Root MTA, BIODENTINE \& Glass Ionomer Cement Using Dye Penetration Method. Materials (Basel). 2021 Jun 8;14(12):3159.Pubmed PMID: 34201321

[22]. Rohit Singh T, Ezhilarasan D. Ethanolic Extract of Lagerstroemia Speciosa (L.) Pers., Induces Apoptosis and Cell Cycle Arrest in HepG2 Cells. Nutr Cancer. 2020;72(1):146-156.Pubmed PMID: 31149840

[23]. Ezhilarasan D. MicroRNA interplay between hepatic stellate cell quiescence and activation. Eur J Pharmacol. 2020 Oct 15;885:173507.Pubmed PMID: 32858048 .

[24]. Romera A, Peredpaya S, Shparyk Y, Bondarenko I, Bariani GM, Abdalla $\mathrm{KC}$, et al. Bevacizumab biosimilar BEVZ92 versus reference bevacizumab in combination with FOLFOX or FOLFIRI as first-line treatment for metastatic colorectal cancer: a multicentre, open-label, randomised controlled trial. The Lancet Gastroenterol Hepatol. 2018 Dec 1;3(12):845-55.

[25]. Raj R K, D E, S R. \-Sitosterol-assisted silver nanoparticles activates Nrf2 and triggers mitochondrial apoptosis via oxidative stress in human hepatocellular cancer cell line. J Biomed Mater Res A. 2020 Sep;108(9):18991908.Pubmed PMID: 32319188.

[26]. Vijayashree Priyadharsini J. In silico validation of the non-antibiotic drugs acetaminophen and ibuprofen as antibacterial agents against red complex pathogens. J Periodontol. 2019 Dec;90(12):1441-1448.Pubmed PMID: 31257588.

[27]. Vijayashree Priyadharsini J, Smiline Girija AS, Paramasivam A. In silico analysis of virulence genes in an emerging dental pathogen A. baumannii and related species. Arch Oral Biol. 2018 Oct;94:93-98.Pubmed PMID: 30015217.

[28]. Uma Maheswari TN, Nivedhitha MS, Ramani P. Expression profile of salivary micro RNA- 21 and 31 in oral potentially malignant disorders. Braz Oral Res. 2020 Feb 10;34:e002.Pubmed PMID: 32049107.

[29]. Gudipaneni RK, Alam MK, Patil SR, Karobari MI. Measurement of the Maximum Occlusal Bite Force and its Relation to the Caries Spectrum of First Permanent Molars in Early Permanent Dentition. J Clin Pediatr Dent. 2020 Dec 1;44(6):423-428.Pubmed PMID: 33378468.

[30]. Chaturvedula BB, Muthukrishnan A, Bhuvaraghan A, Sandler J, Thiruvenkatachari B. Dens invaginatus: a review and orthodontic implications. $\mathrm{Br}$ Dent J. 2021 Mar;230(6):345-350.Pubmed PMID: 33772187.

[31]. Kanniah P, Radhamani J, Chelliah P, Muthusamy N, Joshua Jebasingh Sathiya Balasingh Thangapandi E, Reeta Thangapandi J, et al. Green synthesis of multifaceted silver nanoparticles using the flower extract of Aerva lanata and evaluation of its biological and environmental applications. ChemistrySelect. 2020 Feb 21;5(7):2322-31.

[32]. Bindal P, Bindal U, Dabbagh A, Ramanathan A, Ginjupalli K. Comparative effects of turmeric, coffee, and chew-able tobacco on the color stability of tooth-colored restorative materials. Open J. Dent. Oral Med. 2015 Aug;3(3):59-67.

[33]. Manojlovic D, Lenhardt L, Milićević B, Antonov M, Miletic V, Dramićanin MD. Evaluation of Staining-Dependent Colour Changes in Resin Composites Using Principal Component Analysis. Sci Rep. 2015 Oct 9;5:14638. Pubmed PMID: 26450008.

[34]. Malhotra N, Shenoy RP, Acharya S, Shenoy R, Mayya S. Effect of three indigenous food stains on resin-based, microhybrid-, and nanocomposites. J Esthet Restor Dent. 2011 Aug;23(4):250-7.

[35]. Kanchanavasita W, Anstice HM, Pearson GJ. Water sorption characteristics of resin-modified glass-ionomer cements. Biomaterials. 1997 Jan $1 ; 18(4): 343-9$

[36]. Arora V, Kundabala M, Parolia A, Thomas MS, Pai V. Comparison of the shear bond strength of RMGIC to a resin composite using different adhesive systems: An in vitro study. J Conserv Dent. 2010 Apr;13(2):80-3.Pubmed PMID: 20859480.

[37]. Seghi RR, Hewlett ER, Kim J. Visual and instrumental colorimetric assessments of small color differences on translucent dental porcelain. J Dent Res. 1989 Dec;68(12):1760-4.Pubmed PMID: 2600257.

[38]. Ruyter IE, Nilner K, Möller B. Color stability of dental composite resin materials for crown and bridge veneers. Dent Mater. 1987 Oct 1;3(5):246-51. 